\title{
Analyzing the relationship between cultural intelligence and life satisfaction: Mediating role of career engagement
}

\author{
Sharoon Faran ${ }^{1}$, Dr. Ghulam Dastgeer ${ }^{2}$, Sidra Akhtar ${ }^{3}$
}

\begin{abstract}
The purpose of this article is to examine the relationship of competencies of cultural intelligence with life satisfaction of foreign expatriates who have limited mobility in Pakistan while working here. This relationship is tested with the mediation of Career engagement of the respective individuals. This will assist the understanding of the association of social knowledge of the diverse workforce and will encourage them to oversee it. Workers will feel rationally ensured and will convey results simply more inventively. The personally administered questionnaires were distributed using the snowball ball sampling technique. In total 350 questionnaires were distributed among foreign expatriates. Data were analyzed using SPSS. The results of the study conclude that the foreigners who are working in Pakistan were using their Cultural Intelligence Competencies at their workplace to be having better engagement with the career. However, the hosting companies providing resources to these expatriates so they have a high level of life satisfaction. This is noteworthy, when loaded to slight our decisions to ordinary conditions, explicitly when seeing the issues researchers can need to characterizing the key forecasters of Cultural Intelligence Competencies and life satisfaction in Pakistan. It is found from the current study that expatriates are using their Cultural Intelligence competencies and thus enhance their life satisfaction. Thus, as the organizations are working on the well-being of their employees it is the need of the hour that they should create such an environment where the well-being of the expatriate nourishes.
\end{abstract}

Keywords: Behavioral Cultural Intelligence; Career Engagement; Motivational Cultural Intelligence; Life Satisfaction

\section{JEL Code:}

\section{Introduction}

Universalization makes individuals progressively versatile (Collings, 2014; Mayrhofer $\&$ Reiche, 2014). Individuals these days move crosswise over geological and social limits to take up work and profession openings (Baruch, Budhwar, \& Khatri, 2007).

${ }^{1}$ S Scholar, Air University School of Management-AUSOM, Air University, Islamabad, Pakistan

${ }^{2}$ Assistant Professor, Department of Management \& MIS, College of Business Administration, University of Hail, KINGDOM OF SAUDI ARABIA

${ }^{3}$ Lecturer, University Institute of Management Sciences, Pir Mehr Ali Shah - Arid Agriculture University, Rawalpindi, Pakistan

Corresponding Author: sharoonfaran27@gmail.com

OPEN This work is Licensed under a Creative Commons Attribution-Noncommercial 4.0 International License (c) (8) 
Expatriate, characterized as a deliberate, transitory movement of an individual to abroad for a particular reason with an extreme come back to his/her nation of origin, it is a focal piece of universal business exercises attempted by multinational organizations allinclusive. As indicated by ongoing ILO gauges, there are 150.3 million transient laborers on the planet (Organization, 2015). Dissimilar to customary expatriate wherein associations start the move to another nation, self-started expatriate includes moving to a nation of one's decision to look for work and to set up a more steady profession (Collings, Doherty, Luethy, \& Osborn, 2011). This type of worldwide portability, otherwise called self-started expatriation, is described by moving to another nation without being sent by an organization or a business (Cerdin \& Pargneux, 2010).

Numerous self-started expatriates migrate and move to first world countries which we called the developed countries, for example, the United States, UAE especially Dubai, New Zealand, United Kingdom, and Australia (Doherty, 2013). But now the second world countries which we call the developing countries or the emerging economies taking developmental steps. Since it has extraordinary compared to other administrative structures, practices, and supporting institutional systems for micro-business projects on the planet, Pakistan is viewed as one of the best empowering conditions for economic growth. Thus the Pakistani government has introduced several different development projects with the collaboration of the Chinese government that leads to the hiring of foreign expatriates to Pakistan. Keeping in view, the emergence of foreign expatriates in which a major portion is Chinese workers in different development projects of Pakistan and CPEC as well that is being considered as the major boom in Pakistan's Economy and infrastructure.

For Pakistan, China-Pak Economic Corridor (CPEC) is a destiny changer that brings attraction for foreigners to work in Pakistan, though there was a limited number of foreigners who were working before due to some political, social, economic, and other issues. Be that as it may, in this recently creating relevant setting, social amalgamation rise and have huge consequences on the Pakistani work floor. The Pakistani representatives have some subjective information about the cultures of Chinese and of other nationals. However, to what degree this psychological, social knowledge related to some particular culture may impact the life satisfaction of foreigners who are working in Pakistan. This practice related to culture brought such factors that play a vital role in effective learning of individuals, which creates better chances for their survival in a different culture and their ability is recognized as cultural intelligence.

With 199 million tenants and a populace thickness of 655 thousand occupants for each square kilometer of Arable land, Pakistan is the 6th most crowded nation on the planet (Bureau, 2017). China- Pakistan Economic Corridor is a gathering of foundation extends that are presently under development all through Pakistan. Initially esteemed at $\$ 46$ billion, the estimation of CPEC ventures is currently worth $\$ 62$ billion (Corridor, 2018). As a huge number of projects started into Pakistan that leads to the high attraction of foreigners to work here as such development projects are not only beneficial for 
Pakistan and China but also the neighboring countries of Asia. These projects are supervised through different regional offices like Islamabad, Lahore, and Karachi, etc.

A significant number of these self-began expatriates were crisp or some had a couple of long stretches of work involved in their countries. They referred to financial and vocation-related reasons as powerful in their choice to move and discover professions in another nation. Be that as it may, it is indistinct whether factors other than financial and profession-related reasons affected their choices. Specifically, it is obscure whether they had singular level attributes that controlled or inflame their choice to move to another country to discover better professional openings or we can state the existence fulfillment. Moreover, it isn't certain whether they had been impacted by their versatile assets or by their cultural intelligence and capacities to seek careers abroad and how they assist them with getting engaged with their professions.

In Pakistan, finding the life satisfaction level of foreign employees helps us to understand their career engagement, how utilizing motivational and cultural intelligence will contribute them to gain the maximum level of satisfaction. Taking the glimpse from such cultural practice and from the research study (Le, Jiang, \& Nielsen, 2018) where the relationship of cognitive cultural intelligence and life satisfaction has been studied. According to (Presbitero \& Quita, 2017), the relationship of cognitive cultural intelligence along with life satisfaction has been studied but the other dimensions of cultural intelligence need to be studied in the future in different contexts. So, this study will contribute to literature as it tells future researchers that how foreigners get attracted to work in an emerging economy of a developing country and make available new avenues in the existing literature academically. This study also aims to shed light on the life satisfaction of the foreigners who were working in Pakistan using their cultural intelligence for their career engagement.

On categorizing the aim for this research study is to find a relationship among motivational and behavioral culture intelligence with life satisfaction of foreign expatriates who are working in different organizations in Pakistan. Secondly, this study aims to examine does Career engagement mediates the association between motivational cultural intelligence and life satisfaction as well as does Career engagement mediates the association among behavioral cultural intelligence and life satisfaction.

\section{Literature Review}

\subsection{Cultural Intelligence}

Cultural intelligence is the capacity to make oneself comprehended and to make a productive joint effort in circumstances where social contrasts assume a part. It includes the capacity to act in a fitting route in multicultural circumstances combined with the capacity to have a receptive outlook that concedes new information and is interested in distinction. Usually, there are four main sub- dimensions or components of Cultural intelligence, which are as follows metacognitive, cognitive, motivational, and behavioral cultural intelligence (Van Dyne et al., 2012). Earley and Mosakowski 
(2004a: 139) collaborated to offer the following definition of Cultural intelligence: "a seemingly natural ability to interpret someone's unfamiliar and ambiguous gestures in just the way that person's compatriots and colleagues would, even to mirror them". In another research, Earley, and Ang, in combination with Tan, (2006: 5), extended their earlier definition in defining Cultural Intelligence as "a person's capability for successful adaptation to new cultural settings, that is, unfamiliar settings attributable to cultural context”.

Cognitive cultural intelligence refers to the individual's knowledge about a particular culture, metacognitive cultural intelligence refers to the individuals capacity to understand and acquire the cultural knowledge, motivational cultural intelligence refers to the person's enthusiasm to sustain efforts for proper functioning and the last factor is behavioral cultural intelligence which is the way an individual interacts in a diverse cultural setting (Ang et al., 2015).

\subsection{Life satisfaction:}

Definition of life satisfaction states that "Life satisfaction is a cognitive assessment of an underlying state thought to be relatively consistent and influenced by social factors" (Ellison et al., 1989). The following variable has immense literature with different variables like life satisfaction has been studied with different organizational factors. But recently the researchers found that as the life satisfaction comes from the self-esteem and such other factors which were related to emotions.

The LS has been viewed as hostile welfare state, social expenditure has been studied as a driver of LS and found that levels of government debts has been increasing dure to expense on the program for social protection (Dumbraveanu, 2015). From this we can confer that at national level LS has been a critical issue for the governments.

\subsection{Motivational \& Behavioral Cultural Intelligence with Life Satisfaction:}

Motivational cultural intelligence (MOT) alludes to the psychological ability to coordinate and maintain vitality on a specific assignment or circumstance and perceive that motivational capacities are basic to 'genuine world' critical thinking (Ang et al., 2007). Behavioral Intelligence alludes to outward indications or unmistakable actions: what individuals do as opposed to what they think (Ang et al., 2007). The lifts in globalization and improvement of multi-national associations have delivered thought concerning the piece of worldwide/all-inclusive involvement in organization instruction. In an ongoing report on the understudies of the school who traveled to another country for thinks about, they found that fruitful experience (i.e. achievement, pleasure, individual and vocation development) of these understudies had halfway intervention of MOT in relationship with ethnocentrism and center self- assessment (Barbuto Jr, Beenen, \& Tran, 2015).

Exploration has been conducted at work innovativeness of ostracizes in Chinese MNC's, expressed that metacognitive cultural intelligence and motivational cultural intelligence are without a doubt positive antecedents to social acknowledging, which 
therefore emphatically relates to different social occupation creativity, especially for high region learning ousts who work in a remote culture not hugely not the same as the home culture (Xu and Chen, 2017).

Behavioral cultural intelligence recommends the outward signs or verifiable exercises: what individuals do rather than what they think (Ang et al., 2007). The social insight/cultural intelligence (CQ) has now being contemplated with various factors of HR as said above. As indicated by (Menon, 2015), four zones were distinguished for Asian investigations in which it was the proportions of $\mathrm{CQ}$, the instruction on CQ, preparing of CQ, and enthusiastic work. In an exploration (Bücker, Furrer, Poutsma, \& Buyens, 2014), they guaranteed that almost no work has been done on CQ and its reliant factors by tried in part. They quantified the relationship of CQ, work fulfillment, and correspondence adequacy in Chinese organizations and found that with CQ the nervousness lessened and subsequently prompts viable correspondence.

Taking the purpose of a career in an association, how the self- coordinated profession helps the existence fulfillment. As indicated by (Zhang, Hirschi, Herrmann, Wei, \& Zhang, 2015) under the high level of occupation uncertainty the level of LS will be high and consequently prompted a more grounded association among them. Tourism division likewise discussed the life satisfaction in the setting of significant worth creation by the occupants, in an exploration contemplate by (Lin, Chen, \& Filieri, 2017), found that advancement in tourism prompted high financial advantages which result in a positive effect on LS and esteem creation also.

Feeling weariness has been considered (Boekhorst, Singh, \& Burke, 2017), when it intercedes the relationship of work power and LS, it was discovered that the workforce has a negative association with life satisfaction. Besides the mental unprejudiced nature expels the negative connection between enthusiastic weariness and life satisfaction.

Cultural intelligence has also been studied with moderating role of idiocentrismallocentrism in MNCs culture taking work engagement as a dependent variable using conservation of resources theory (Gabel-Shemueli, Westman, Chen, \& Bahamonde, 2019) and it has been found that a positive relationship exists among them as there very few studies where the motional factor-like involvement/engagement have been studied before. Thus, it has been suggested by the authors as well that other dimensions of cultural intelligence should be studied with personal engagement factors.

The researchers also studied an element related to behavioral cultural intelligence, in a research study (Charoensukmongkol \& Pandey, 2020), the effect of the cultural intelligence (CQ) of salespeople, who engage in cross- cultural selling, on the quality of cross-cultural sales presentations has been studied. The research showed a significant effect of sales-efficacy that partially mediates the association of cultural intelligence and cross-cultural sales presentations. 
The relationship between innovative work behaviors and cultural intelligence has also been studied, it has been found that Cultural intelligence can essentially influence a representative's inventive work conduct. It further uncovers that both work commitment and relational trust somewhat intercede the impact of social insight on imaginative work conduct (Afsar, Al-Ghazali, Cheema, \& Javed, 2020). Therefore, this study proposes that

Hypothesis 1: Motivational cultural intelligence has a positive impact on life satisfaction

Hypothesis 2: Behavioral cultural intelligence has a positive impact on life satisfaction

\subsection{Career Engagement as Mediator}

Career Engagement is how much some person is proactively building up his or her career as communicated by assorted professional practices (Hirschi, Freund, \& Herrmann, 2014). Starting late, examiners have battled that the effect of identity properties i.e., narcissism can be passed on to one's sentiment of satisfaction through the limit of calling duty. According to (Hirschi \& Jaensch, 2015), found that there is a relationship of personality traits i.e. narcissism with career success mediated positively with career engagement.

In agreement with (King, 2004), expecting obligation for a person's vocation is basic to make constructive self-progression, which is found to dependably relate to calling satisfaction. From the CQ perspective, scholarly CQ to some point can be seen as a sort of mental capital that vagrants may use to oversee sudden conditions in various life settings including calling events of widespread transient representatives (Dollwet \& Reichard, 2014).

Proactive people fill in as a demeanor antecedent of work duty and work responsibility mediated proactive character's relationship with work satisfaction and not completely interceded its relationship with professional satisfaction and life satisfaction (Jawahar \& Liu, 2017).

Keeping this perspective; an exploration think about has been led on the educators' career engagement (McIlveen \& Perera, 2016), it was discovered that identity of the instructor associated with career engagement when interceded with professional positive thinking.

Hypothesis 3: Career engagement mediates the relationship between motivational cultural intelligence and life satisfaction

Hypothesis 4: Career engagement mediates the relationship between behavioral cultural intelligence and life satisfaction 


\subsection{Geert Hofstede Cultural theory (Overarching theory):}

Hofstede's theory depicts the impacts of a general public's way of life on the estimations of its individuals, and how these qualities identify with conduct, utilizing a structure got from factor investigation. According to theory (Hofstede, 1983), he has proposed four dimensions of culture that affects individual psychology which he named as power distance (the degree to which the members of a society accept the culture of unequal distribution of power in the society, it usually has the steep hierarchy), uncertainty avoidance (the degree to which members feel uncomfortable with risk and uncertainty), individualism $\mathrm{v} / \mathrm{s}$ collectivism (the extent to which people are supposed to take care of themselves leads to individualism however they collectively look after each leads to the collective culture of the society) and masculinity v/s femininity ( In masculinity, cultures emphasize more on three things i.e. achievement, assertiveness, and material success. Where we talk about the femininity it emphasizes on modesty, caring and quality of life). The current study takes the reference of Hofstede's 1983 theory as it is found more suitable with the variables under the current study.

\subsection{Conceptual Framework}

The following figure 1 illustrates the conceptual framework of this study. The relationship between motivational and behavioral cultural intelligence is initially investigated with life satisfaction, which is later followed by the testing of mediating role of career engagement for foreign expatriates in Pakistan.

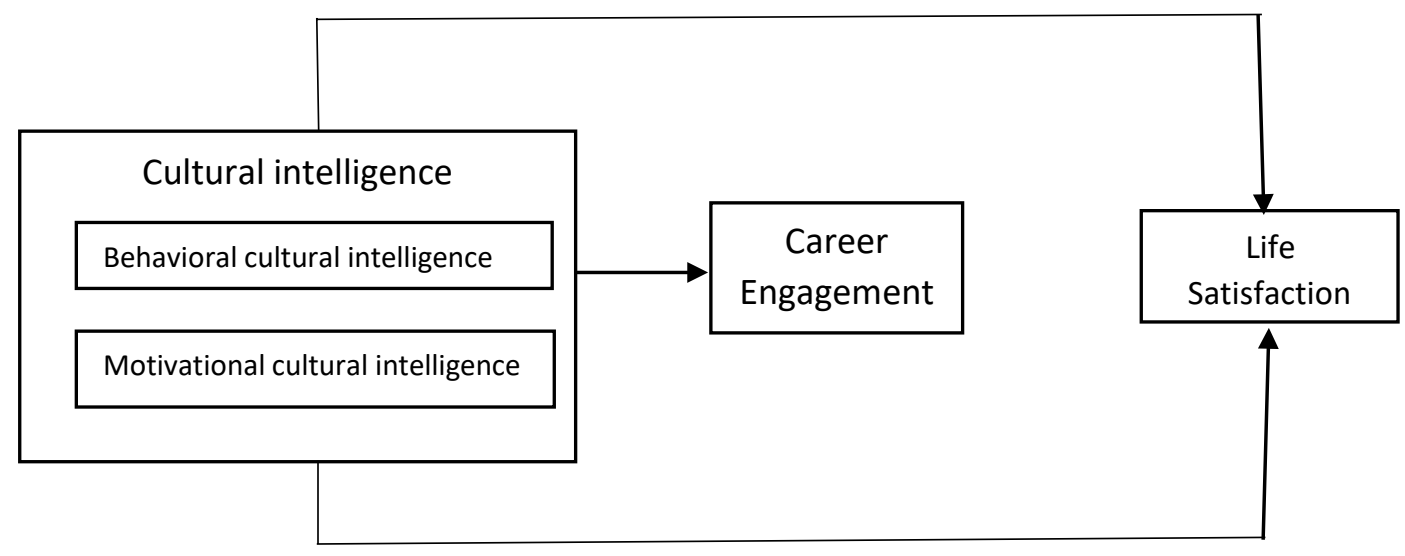

Figure 1. Conceptual Framework

\section{Methods}

\subsection{Sample and data collection}

To test the hypothesis of the current study, this research study was directed in two big cities of Pakistan Islamabad and Lahore focusing on the organizations where the nonnatives are working predominantly like IT organizations in Islamabad and assembling ventures in Lahore. As the nonnatives are confronting constrained 
versatility in Pakistani zones and are staying with strict tenets and controls alongside the security concerns. So despite confronting every one of the difficulties do they feel happy with their lives and how the social standards and qualities influence their life fulfillment. Using $\mathrm{G}^{*}$ Power 3.1.9.2, the sample size determined using two predictors we have 74 in number the sample for the study. So the questionnaires were distributed using the snowball sampling technique. Around 350 questionnaires were distributed out of which we have received 165 back from different employees of private organizations. Approximately Seventy percent $(70 \%)$ were males and thirty percent $(30 \%)$ were females. The participants were sampled from a population of employees who were working on different development projects in Lahore and IT-based companies in Islamabad. Due to the legal and security concerns of the foreigners, the appointments were first taken through emails, and after that, the researchers met them, moreover, the researchers used referrals who were working with them and collect data from them as well.

\subsection{Survey development \& Pilot testing}

An overview instrument was at first created and pilot testing with a small number of foreign expatriates working in Islamabad $(n=15)$. This was to enable the analysts to guarantee that the inquiries, things, and language of the overview were proper and clear to the objective respondents. After the pilot testing, it was shown that the research study was understandable and clear to the respondents, and effortlessly comprehended by the foreign expatriates in Pakistan.

The survey was controlled utilizing a pen and paper approach. The survey, which was directed by one of the researchers, was first given morals endorsement by the workers. The morals endorsement required de-recognizable proof of the individual data of respondents, and additionally deliberate involvement in the research survey. Henceforth, in the initial area of the survey, the general points and objectives of the research study were mentioned together. Additionally, the members were requested to sign the informed agree segment to show their willful cooperation in the investigation.

The response for all variables utilized are measured against a 7-point Likert scale (where $1=$ strongly disagree, and $7=$ strongly agree.). The questionnaires clearly stated that all the particulars gathered from them should be kept confidential and used for academic research study only. The sources that are used in the study are mentioned in the table. 


\begin{tabular}{|c|c|c|c|}
\hline Construct & $\begin{array}{l}\text { No o } \\
\text { items }\end{array}$ & f Source & Example items \\
\hline $\begin{array}{l}\text { Motivational } \\
\text { cultural } \\
\text { intelligence }\end{array}$ & 5 & $\begin{array}{ll}\text { Ang } & \text { et } \\
& \text { al. } \\
(2007) & \end{array}$ & $\begin{array}{l}\text { "I enjoy interacting with people from different } \\
\text { cultures". "I am confident that I can socialize } \\
\text { with locals in a culture that is unfamiliar to me" }\end{array}$ \\
\hline $\begin{array}{l}\text { Behavioral } \\
\text { cultural } \\
\text { intelligence }\end{array}$ & 5 & $\begin{array}{ll}\text { Ang } & \text { et } \\
& \text { al. } \\
(2007) & \end{array}$ & $\begin{array}{l}\text { "I change my verbal behavior (e.g., accent, } \\
\text { tone) when a cross-cultural interaction requires } \\
\text { it". "I use to pause and silence differently to } \\
\text { suit different cross-cultural situations". }\end{array}$ \\
\hline $\begin{array}{l}\text { Life } \\
\text { satisfaction }\end{array}$ & 5 & $\begin{array}{l}\text { Diener, } \\
\text { Emmons, } \\
\text { Larsen, and } \\
\text { Griffin } \\
(1985)\end{array}$ & $\begin{array}{l}\text { "In most ways, my life is close to my ideal". } \\
\text { "The conditions of my life are excellent". }\end{array}$ \\
\hline $\begin{array}{l}\text { Career } \\
\text { engagement }\end{array}$ & 9 & $\begin{array}{l}\text { Hirschi et } \\
(2014)\end{array}$ & $\begin{array}{l}\text { al. "Actively sought to design your professional } \\
\text { future". } \\
\text { "Undertook things to achieve your career } \\
\text { goals". }\end{array}$ \\
\hline
\end{tabular}

\section{Results:}

\subsection{Descriptive and correlation Analysis}

As shown in the table, for independent variables motivational cultural intelligence and behavioral cultural intelligence, we have their mean value as 5.7107 and 5.5113 respectively, which shows that the respondents are above average a gree on the scale of $\mathrm{MCI}$ and BEH. From this, it is also shown that most of the expatriates are using their cultural competencies on the Pakistani Work floor.

Likewise, for our dependent variable life satisfaction, we have the mean value 5.2685 and its standard deviation value as .87130 which also gives us a view that the majority of the expatriates had a good level of life satisfaction. And for the case of our mediator, career engagement we have its mean value of 5.8396 which shows a good level of the agreeableness of the expatriates with their career at their workplace. The table below shows the values of correlation between IVs, DV, and mediator. 
Table 2. Descriptive and correlation analysis

\begin{tabular}{|l|l|l|l|l|l|l|l|l|}
\hline Constructs & $\mathbf{N}$ & Alpha & Mean SD & $\begin{array}{l}\text { Motivational } \\
\text { Cultural } \\
\text { Intelligence }\end{array}$ & $\begin{array}{l}\text { Behavioral } \\
\text { Cultural } \\
\text { Intelligence }\end{array}$ & $\begin{array}{l}\text { Career } \\
\text { Engagement }\end{array}$ & $\begin{array}{l}\text { Life } \\
\text { Satisfaction }\end{array}$ \\
\hline $\begin{array}{l}\text { Motivational } \\
\text { cultural } \\
\text { Intelligence }\end{array}$ & 248 & 0.827 & 5.7107 & 1.00 & 1 & & & \\
\hline $\begin{array}{l}\text { Behavioral } \\
\begin{array}{l}\text { Cultural } \\
\text { Intelligence }\end{array}\end{array}$ & 248 & 0.884 & 5.5113 & 0.85 & $.755^{* *}$ & 1 & & \\
\hline $\begin{array}{l}\text { Career } \\
\text { engagement }\end{array}$ & 248 & 0941 & 5.8396 & 0.77 & $.688^{* *}$ & $.614^{* *}$ & 1 & \\
\hline $\begin{array}{l}\text { Life } \\
\text { satisfaction }\end{array}$ & 248 & 0.820 & 5.2685 & 0.87 & $.257^{* *}$ & $.270^{* *}$ & -0.034 & 1 \\
\hline
\end{tabular}

\subsection{Reliability analysis}

Conferring to Hair et al. (2006) reliability measures the internal consistency of the construct. The following table 2 confirms that all the constructs showed an acceptable level of reliability under the recommended value of alpha 0.70 (Hair et al. 2006).

Table 3. The Mediating Role of Career engagement on Motivational Cultural Intelligence and Life Satisfaction

\begin{tabular}{|l|l|l|l|}
\hline & $\beta$ & $t$ & $P$ \\
\hline Motivational cultural intelligence career & 0.5868 & 14.8871 & 0.0000 \\
\hline Career engagement life satisfaction (b) & -0.4523 & -4.9548 & 0.0000 \\
\hline $\begin{array}{l}\text { Motivational cultural intelligence life } 0.2466 \\
\text { satisfaction (c) }\end{array}$ & 4.1751 & 0.0000 \\
\hline Direct effect (c') & 0.5121 & 6.5809 & 0.0000 \\
\hline Bootstrap result(sample size 5000) for & Indirect effect & 0.0000 \\
\hline
\end{tabular}

Sukkur IBA Journal of Management and Business - SIJMB | Vol 8 No. 2 July - December 2021 ๑ Sukkur IBA University 

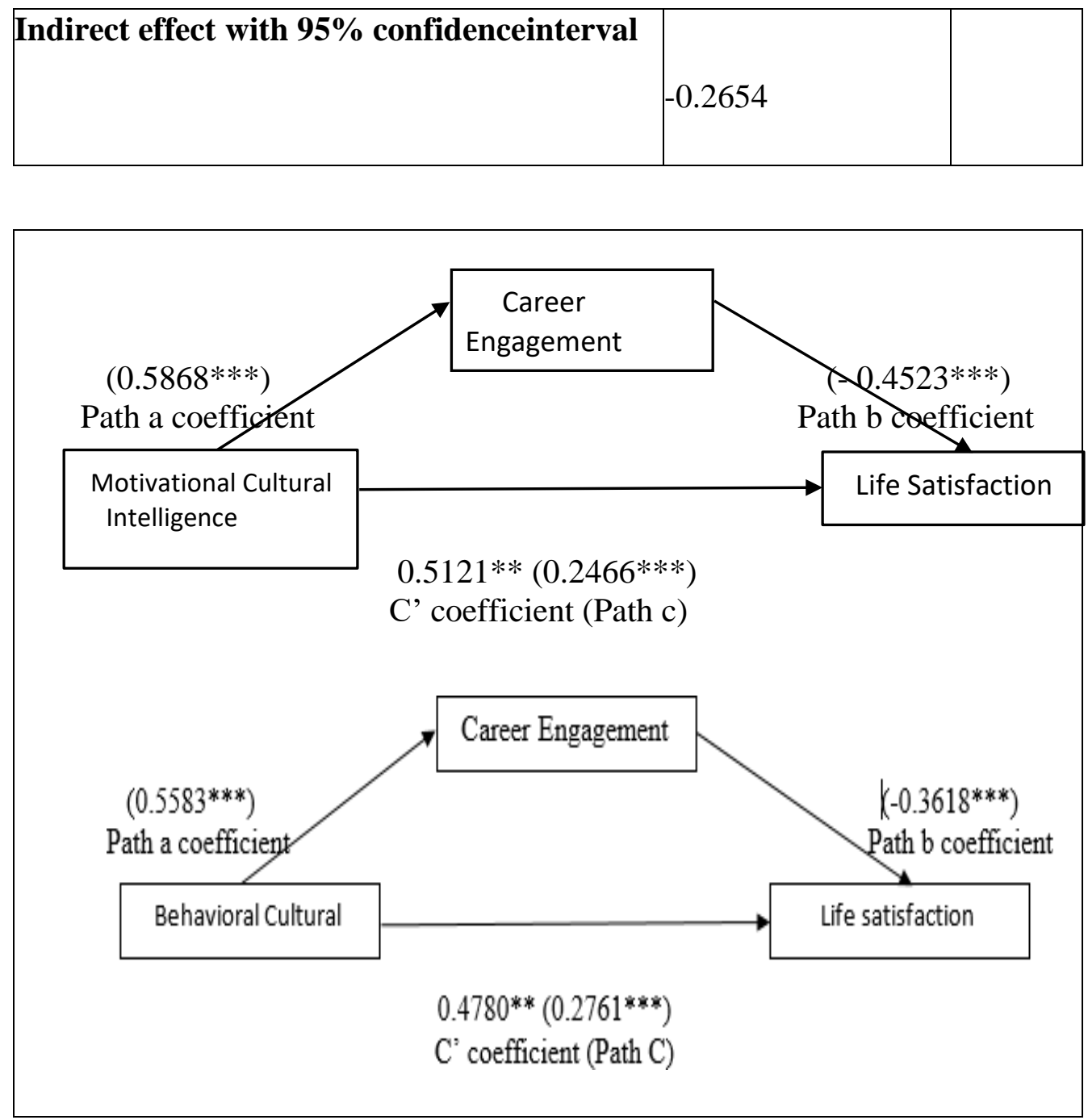

Figure 2. The Mediating Role of Career Engagement on the relationship between Motivational Cultural Intelligence and Life Satisfaction b) The Mediating Role of

Career engagement on Behavioral Cultural Intelligence and Life Satisfaction

\subsection{Regression Analysis}

The table above is representing the path effects of motivational cultural intelligence and life satisfaction via career engagement as a mediator. Firstly, path 'a' showed a positive and significant relationship between Motivational cultural intelligence and Career Engagement $(\beta=0.5868, \mathrm{p}=0.0000)$. Moving to path $\mathrm{b}$; a negative but significant relationship exists among the Career Engagement and Life Satisfaction $(\beta=-0.4523$, $\mathrm{p}=0.0000)$. Lastly, path $\mathrm{c}$ is showing the significant value between Motivational cultural intelligence and Life Satisfaction $(\beta=0.2466, p=0.0000)$. (hypothesis 1$)$ 
Both path (a) and path (b) were significant, the mediation analysis was tested using the bootstrapping method with bias-corrected confidence estimates (MacKinnon, Lockwood, \& Williams, 2004; Preacher \& Hayes, 2004). In the present study, the 95\% confidence interval of the indirect effects was obtained with 5000 bootstraps resamples (Preacher \& Hayes, 2008).

The results of the mediation analysis have confirmed the mediating role of career engagement in the relationship of motivational cultural intelligence and life satisfaction $(\beta=0.2654$; bootstrap results of the indirect effect). Adding to this, the results indicated that the direct effect of motivational cultural intelligence on life satisfaction became significant $(\beta=0.5121, \mathrm{t}=6.5809, \mathrm{p}=.0000) \mathrm{c}^{\prime}$ path, when controlling for career engagement, thus resulting in partial mediation. (hypothesis 3 )

The table above is representing the path effects of behavioral cultural intelligence and life satisfaction via career engagement as a mediator. Firstly, path 'a' showed a positive and significant relationship between behavioral cultural intelligence and career engagement $(\beta=0.5583, p=0.0000)$. Moving to path $b$; a negative but significant relationship exists between career engagement and life satisfaction $(\beta=-0.3818$, $\mathrm{p}=0.0000)$. Lastly, path $\mathrm{c}$ is showing the significant value among behavioral cultural intelligence and LS ( $\beta=-0.2761, p=0.0000)$. (hypothesis 2$)$. Both path (a) and path (b) were significant, the mediation analysis was tested using the bootstrapping method with bias- corrected confidence estimates (MacKinnon, Lockwood, \& Williams, 2004; Preacher \& Hayes, 2004). In the present study, the 95\% confidence interval of the indirect effects was obtained with 5000 bootstraps resamples (Preacher \& Hayes, 2008).

The results of the mediation analysis have confirmed the mediating role of career engagement in the relationship of motivational cultural intelligence and life satisfaction ( $\beta=0.2020$; bootstrap results of the indirect effect) Adding this, the results indicated that the direct effect of motivational cultural Intelligence on life satisfaction became significant $(\beta=0.4780, t=6.2170, \mathrm{p}=0.000) \quad \mathrm{c}$ path when controlling for career engagement, thus resulting into partial mediation (hypothesis 4).

Table 4. The Mediating Role of Career engagement on Behavioral Cultural Intelligence and Life Satisfaction

\begin{tabular}{|l|l|l|l|}
\hline & $\beta$ & $\mathrm{T}$ & $\mathrm{P}$ \\
\hline $\begin{array}{l}\text { Behavioral cultural intelligence } \rightarrow \text { career } \\
\text { engagement (a) }\end{array}$ & & & \\
\hline Career engagement $\rightarrow$ life satisfaction (b) & -0.3818 & -12.2072 & 0.0000 \\
\hline $\begin{array}{l}\text { Behavioral cultural intelligence } \rightarrow \operatorname{life} \\
\text { satisfaction (c) }\end{array}$ & 0.2761 & 4.3978 & 0.0000 \\
\hline
\end{tabular}




\begin{tabular}{|ll|l|l|l|}
\hline Direct effect (c') & 0.4780 & 6.2170 & 0.0000 \\
\hline Bootstrap(sample size $\mathbf{5 0 0 0}$ ) & $\begin{array}{c}\text { result for } \\
\text { Indirect effect with } \mathbf{9 5 \%} \\
\text { confidence }\end{array}$ & & \\
interval & Indirect effect & 0.0000 \\
& & & \\
& & & \\
\end{tabular}

\section{Discussion}

The prime focus of this section is to explain the results of the developed hypothesis for the current study. As the study tried to find out the impact of motivational cultural intelligence and behavioral cultural intelligence on the life satisfaction of the foreign expatriates who were working in Pakistan. Moreover; does career engagement affect the relationship of the above-mentioned variables when it acts as a mediator? For this, the PROCESS Method by Andrew F. Hayes has been used to test the hypothesis.

The results of our first objective of the study show that the life satisfaction of the foreigner who was working in Pakistan get affected by the motivational cultural intelligence as the individuals enjoyed interacting with the people of different cultures. The findings are similar to the results of the previous study (Le, Jiang, \& Nielsen, 2016) where cognitive cultural intelligence was found to have a significant relationship with the life satisfaction of the migrants' worker. Foreign expatriates use their capability of motivational culture while working in Pakistan and it facilitates them to have a good level of life satisfaction despite having limited mobility and other protocols both the variables under study have a positive and significant relationship among them and led us to accept the first hypothesis of this study.

The second hypothesis is also accepted in light of the above data analysis. The results have shown that a significant and positive relationship existed among behavioral cultural intelligence and life satisfaction of the foreign expatriates. It has been proved that the individuals change their verbal and non-verbal behavior when an inter-cultural gathering demands from them i.e. at the Pakistani work floor they respect and practice the norms, values of the host country nationals which result in strong bonding among individuals. The study has shown that like cognitive cultural intelligence the other dimension of cultural intelligence i.e. behavioral cultural intelligence has a positive and significant relationship with life satisfaction (Le, Jiang, \& Nielsen, 2018).

The third hypothesis that deals with mediating effect of career engagement with motivational cultural intelligence and life satisfaction showed a significant relationship 
using bootstrapping technique. The results have shown negative mediation among the variables, which showed that the mediating variable i.e. career engagement increased its effect when involved among motivational cultural intelligence and life satisfaction of the foreign expatriates. The researchers (Luke, 2015) used to term this effect as suppression. As the traditional use of mediators was found to decrease the effect but here the results have shown that career engagement increases its mediating role among the aforementioned variables.

The results have shown that the fourth hypothesis of this study has been accepted as career engagement mediates the relationship of behavioral cultural intelligence and life satisfaction of the foreigners who were working in Pakistan. The relationship among the variables is significant. The results have shown that like motivational cultural intelligence, career engagement negatively mediates the relationship between behavioral cultural intelligence and life satisfaction. According to a research study (Le et al., 2018), career engagement mediates the relationship of cognitive cultural intelligence and life satisfaction when social injustice moderates the relationship. Thus, the current study confirmed that career engagement affects the relationship of life satisfaction with other dimensions of cultural intelligence i.e. motivational and behavioral cultural intelligence which have been studied in this study.

\subsection{Practical implications of the study}

It has been found from the current study that expatriates are using their Cultural Intelligence competencies and thus enhance their life satisfaction. Thus, as the organizations are working on the well-being of their employees it is the need of the hour that they should create such an environment where the well- being of the expatriate nourishes.

This study helps the organizations in developing more effective policies for their overseas employees and can effectively engage them at the workplace, by showing the importance of the CQ role in getting a high level of life satisfaction.

The organization needs to arrange some activities that can enhance the life satisfaction of the foreign employee as the results showed indirect mediation with a significant relationship between career engagement and life satisfaction. Thus, the context of the activities should be like that it affects life satisfaction in such a manner that it can decrease that indirect effect. This study also let the

organizations know about the enhancement of adaptive and contextual performance of their foreign employees. Experiential learning of the employees also gets improved when the organizations gave international assignments to their employees. This study will help to understand the cultural amalgamation at Pakistani work floor which has been studied very little before especially for the foreigners who work there, Thus, the reader can get an insight into the competencies of cultural intelligence and HR practices. This study will also contribute to the literature of life satisfaction of foreign expatriates

Sukkur IBA Journal of Management and Business - SIJMB | Vol 8 No. 2 July - December 2021 @ Sukkur IBA University 
with motivational and behavioral cultural intelligence with respective to Pakistani context.

\subsection{Contribution of the study}

This study will contribute to the existing literature on CQ and life satisfaction by identifying new horizons for future research in Pakistan and can be adopted as a piece of guidance to the Pakistani business owner to maintain a diverse workforce by taking care of their life satisfaction via career engagement by providing them social justice. Workers will feel rationally secured and will convey results simply more innovatively. By this examination think about, the associations can attract a more viable workforce as a more tried and true relationship in labor laws and legal and moral attributes. In the proximity of result masterminded culture, delegates will get a chance to make their occupations in fascinating ways.

\section{Conclusion:}

The researchers of the current study are quite confident about the optimistic future of the CQ competencies with Life satisfaction in our country. As Pakistan is moving towards new horizons of success in which it gets support to excel from the neighboring country China, several projects have been started

Under CPEC or other development projects. But, this is the start for the Pakistan people and they also need to know CQ. From the current findings, the results are above average which can be improved over time. Career engagement with life satisfaction needs more attention in Pakistan to be focused on by the employers while using CQ competencies. But what matters is that;

- Do the employers give importance to CQ at their workplace?

- Does the parent company providing resources to the expatriates in the host country i.e. Pakistan to have the maximum level of life satisfaction?

- Are our HR sections fully involved during the employee strategic planning process?

As the international companies now focusing on psychological HRM, the soft side of HRD to excel and improve their workplace for their employees. Pakistan needs to focus on this, it is time to move ahead and learn about the international HR practices with implementation at the workplace using the CQ. In this way, a more effective diverse workforce was maintained.

\subsection{Limitations and directions for future research}

Following limitations were faced by the researchers, firstly the sample size of the study is less in number as the respondents were foreign expatriates and due to security concerns, they were not easily assessable. Secondly, the study is cross-sectional as the 
data was collected in one shot but if the study is longitudinal we can get more reliable results as compared to the current study. Thirdly, as the security concerns were high so the appointment to fill up the questionnaire was done through email and some organizations replied and give us an appointment but one of them had the questionnaires but didn't give us back.

For future researchers, it is recommended to target the big number of foreign expatriates who are working under different projects like CPEC, etc. The researchers can conduct this study in time lag to get more realistic results. Different moderation and mediation can be used such as language ability, employee value proposition as a mediator, and perception of organizational politics as a moderator between cultural intelligence and life satisfaction.

\section{Author Contributions:}

Mr. Sharoon Faran: The main idea of research paper is contributed by first author and he has written the research questions, introduction, literature review and conceptual framework.

Dr. Ghulam Dastgeer: The second author of research paper has analyzed the data by using SPSS, and has also contributed in interpreting of results.

Ms. Sidra Akhtar: The third author of paper has collected data from respondents, prepared data set and contributed in writing the conclusion, discussion section of research paper and provided the overall review of the study.

\section{Data Availability Statement:}

Yes, collected data is available in the shape of data set.

\section{Conflict of Interest:}

There is no conflict of interest.

\section{Funding Information:}

There is no internal or external funding resources available for this study.

\section{References}

Afsar, B., Al-Ghazali, B. M., Cheema, S., \& Javed, F. (2020). Cultural intelligence and innovative work behavior: the role of work engagement and interpersonal trust. European Journal of Innovation Management.

Ang, S., Van Dyne, L., Koh, C., Ng, K. Y., Templer, K. J., Tay, C., \& Chandrasekar,

N. A. (2007). Cultural intelligence: Its measurement and effects on cultural judgment and decision making, cultural adaptation, and task performance. Management and organization review, 3(3), 335-371. 
Barbuto Jr, J. E., Beenen, G., \& Tran, H. (2015). The role of core self-evaluation, ethnocentrism, and cultural intelligence in study abroad success. The International Journal of Management Education, 13(3), 268-277.

Baruch, Y., Budhwar, P. S., \& Khatri, N. (2007). Brain drain: Inclination to stay abroad after studies. Journal of World Business, 42(1), 99-112.

Boekhorst, J. A., Singh, P., \& Burke, R. (2017). Work intensity, emotional exhaustion and life satisfaction: the moderating role of psychological detachment. Personnel Review, 46(5), 891-907.

Bücker, J. J., Furrer, O., Poutsma, E., \& Buyens, D. (2014). The impact of cultural intelligence on communication effectiveness, job satisfaction and anxiety for Chinese host country managers working for foreign multinationals. The International Journal of Human Resource Management, 25(14), 2068-2087.

Bureau, P. R. (2017). World Population Data Sheet.

Cerdin, J. L., \& Pargneux, M. L. (2010). Career anchors: A comparison between organizationassigned and self-initiated expatriates. Thunderbird International Business Review, 52(4), 287-299.

Charoensukmongkol, P., \& Pandey, A. (2020). The influence of cultural intelligence on sales self-efficacy and cross-cultural sales presentations: does it matter for highly challengeoriented salespeople? Management Research Review.

Collings, D. G. (2014). Integrating global mobility and global talent management: Exploring the challenges and strategic opportunities. Journal of World Business, 49(2), 253-261.

Collings, D. G., Doherty, N., Luethy, M., \& Osborn, D. (2011). Understanding and supporting the career implications of international assignments. Journal of Vocational Behavior, 78(3), 361-371.

Corridor, C. P. E. (2018). CPEC Significance/Potential.

Diener, E., Emmons, R. A., Larsen, R. J., \& Griffin, S. (1985). The satisfaction with life scale. Journal of personality assessment, 49(1), 71-75.

Doherty, N. (2013). Understanding the self-initiated expatriate: A review and directions for future research. International Journal of Management Reviews, 15(4), 447-469.

Dollwet, M., \& Reichard, R. (2014). Assessing cross-cultural skills: Validation of a new measure of cross-cultural psychological capital. The International Journal of Human Resource Management, 25(12), 1669-1696.

Gabel-Shemueli, R., Westman, M., Chen, S., \& Bahamonde, D. (2019). Does cultural intelligence increase work engagement? The role of idiocentrism-allocentrism and organizational culture in MNCs. Cross Cultural \& Strategic Management.

Hirschi, A., Freund, P. A., \& Herrmann, A. (2014). The career engagement scale: Development and validation of a measure of proactive career behaviors. Journal of Career Assessment, 22(4), 575-594.

Hirschi, A., \& Jaensch, V. K. (2015). Narcissism and career success: Occupational self- efficacy and career engagement as mediators. Personality and Individual Differences, 77, 205-208.

Jawahar, I., \& Liu, Y. (2017). Why are proactive people more satisfied with their job, career, and life? An examination of the role of work engagement. Journal of Career Development, 44(4), 344-358.

King, Z. (2004). Career self-management: Its nature, causes and consequences. Journal of Vocational Behavior, 65(1), 112-133.

Le, H., Jiang, Z., \& Nielsen, I. (2016). Cognitive cultural intelligence and life satisfaction of migrant workers: The roles of career engagement and social injustice. Social Indicators Research, 1-21.

Sukkur IBA Journal of Management and Business - SIJMB | Vol 8 No. 2 July - December 2021 () Sukkur IBA University 